\title{
Evaluating the sensitivity of jurisdictional-heterogeneity and jurisdictional-mixing in national-level HIV prevention analyses: Context of the U.S. Ending the HIV Epidemic goal.
}

\author{
Hanisha Tatapudi \\ University of South Florida \\ Chaitra Gopalappa ( $\sim$ chaitrag@umass.edu ) \\ University of Massachusetts Amherst
}

\section{Research Article}

Keywords: jurisdictional-mixing, jurisdictional-heterogeneity, HIV/AIDS, HIV intervention analysis, Ending the HIV Epidemic (EHE) plan, dynamic compartmental model, simulation

Posted Date: February 3rd, 2022

DOI: https://doi.org/10.21203/rs.3.rs-1220584/v1

License: (c) (i) This work is licensed under a Creative Commons Attribution 4.0 International License. Read Full License 


\section{Abstract}

Background:

The U.S. Ending the HIV epidemic (EHE) plan aims to reduce annual HIV incidence by $90 \%$ by 2030 , by first focusing interventions on 57 jurisdictions (county or state) (EHE-jurisdictions) that contributed to more than $50 \%$ of annual HIV diagnoses. Mathematical models that simulate future HIV incidence projections help evaluate the impact of interventions and inform intervention decisions. However, current models are either national-level, which do not consider jurisdictional-heterogeneity, or independent jurisdiction-specific, which do not consider cross jurisdictional interactions. Data suggests that significant proportion of persons have sexual-partnerships with persons outside their own jurisdiction. However, the sensitivity of these jurisdictional interactions on model outcomes and intervention decisions have not been studied.

\section{Methods:}

We developed a compartmental simulation of HIV in the U.S., through composition of 57 EHE and 46 non-EHE jurisdictions, with populations interacting across jurisdictions through sexual partnerships. To evaluate sensitivity of jurisdictional interactions on model outputs, we analyzed 16 scenarios, combinations of proportion of sexualpartnerships mixing outside jurisdiction: no-mixing, low-level-mixing-within-state, high-level-mixing-within-state, or high-level-mixing-within-and-outside-state; jurisdictional-heterogeneity in care and demographics: homogenous or heterogeneous; and intervention assumptions for 2019-2030: baseline or EHE-plan (diagnose, treat, and prevent).

Results:

Change in incidence in mixing compared to no-mixing scenarios varied by EHE and non-EHE jurisdictions and aggregation-level. When assuming jurisdictional-heterogeneity and baseline-intervention, while the change in aggregated incidence ranged from $-2 \%$ to $0 \%$ for EHE and $5 \%$ to $21 \%$ for non-EHE, within each jurisdiction it ranged from $-31 \%$ to $46 \%$ for EHE and $-18 \%$ to $109 \%$ for non-EHE. Thus, incidence estimates were sensitive to jurisdictionalmixing more at the jurisdictional-level. As a result, jurisdiction-specific HIV-testing intervals inferred from the model to achieve the EHE-plan were also sensitive, e.g., when no-mixing scenarios suggested testing every 1 year (or 3 years), the three mixing-levels suggested testing every 0.8 to 1.2 years, 0.6 to 1.5 years, and 0.6 to 1.5 years, respectively (or 2.6 to 3.5 years, 2 to 4.8 years, and 2.2 to 4.1 years, respectively). Similar patterns were observed when assuming jurisdictional-homogeneity, however, change in incidence in mixing compared to no-mixing scenarios were high even in aggregated incidence.

\section{Conclusions:}

Accounting for jurisdictional-mixing and jurisdictional-heterogeneity could help improve model-based analyses.

\section{Introduction}

In the United States (U.S.), there were an estimated 1.18 million people living with HIV (PWH) as of 2019, and an estimated average of 36,500 new infections each year between 2015 and 2019 [1]. Although HIV disease has no cure, consistent use of antiretroviral therapy treatment (ART) by infected persons can fully suppress viral load, thus preventing transmissions [2]. Further, pre-exposure prophylaxis (PrEP) for high-risk susceptible individuals can reduce HIV acquisition by $99 \%$ [3]. However, there are considerable gaps in administering these preventive tools. As of 2019, nationally, $87 \%$ of PWH were aware of their infection (proportion aware), but only $66 \%$ of those aware were on ART

Page 2/26 
with viral load suppression (proportion with VLS) [4]. Among susceptible persons with PrEP eligibility, only $23 \%$ were administered PrEP (PrEP coverage). In addition, there is considerable heterogeneity in these care gaps by age, riskgroup, and jurisdictions. Across geographical jurisdictions in the U.S., the proportion aware ranged from 80-96\%, the proportion with VLS ranged from 49-83\%, and PrEP coverage ranged from 6-93\% [4]. Taking these jurisdictional disparities into consideration, the most recent U.S. national strategic plan, Ending the HIV Epidemic (EHE) [5], [6], in addition to continuing the age and risk-group focused efforts as in the previous national plan [7], also aims for jurisdictional focused efforts. Specifically, the EHE plan first aims to reduce national incidence by $75 \%$ by 2025 by focusing prevention efforts in 50 counties and 7 states (we will refer to these as the EHE jurisdictions), which had accounted for more than $50 \%$ of nationwide diagnoses in 2017, and secondly, reduce incidence by $90 \%$ by 2030 by expanding prevention efforts to the rest of the nation (we will refer to these as the non-EHE jurisdictions) [5]. Diagnose (through increases testing), treat (through increased care linkage and retention), prevent (through PrEP) are three of the four strategic pillars of the EHE prevention efforts. Specially, the goal is to reach care continuum targets of 95-95-95 (i.e., 95\% awareness of infection status among PWH, 95\% linkage to care among those aware, and 95\% VLS among those in care) and PrEP coverage of 50\% among those eligible for PrEP, by 2025 in EHE jurisdictions, and by 2030 in all jurisdictions nation-wide [8].

Mathematical models that simulate future HIV incidence projections help evaluate the impact of interventions and inform intervention decisions. Recent literature includes multiple jurisdiction-specific models [9-17] and nationallevel models $[18,19]$ that have conducted intervention analyses related to the U.S. EHE plan. The jurisdiction-specific models cover limited EHE jurisdictions, and, each jurisdiction is evaluated independently, which ignores the interactions between jurisdictions, specifically, the sexual partnership mixing between persons of different jurisdictions [20-25]. On the other hand, the national-level models do not consider the jurisdictional-heterogeneity in population demographics, including population size of key risk-groups such as injecting drug users and men who have sex with men (MSM) [26], and care parameters noted above, or the interactions between jurisdictions. Jurisdictional-heterogeneity in demographics and care along with partnership mixing between jurisdictions [20-25] suggest that there is potential for strategies adopted in one jurisdiction to influence the nation-wide HIV incidence. However, the influence of these jurisdictional interactions, in light of the EHE plan, has not been studied, and there are multiple gaps preventing such analyses. First, such a study is infeasible to conduct using the current type of independent jurisdiction-specific or generalized national-level models alone. Second, large-scale national-level data for partnership mixing such as from behavioral surveys are limited, and infeasible to generate for every jurisdiction pair. Third, though current model types do not simulate jurisdictional interactions, it is not clear if and to what magnitude do jurisdictional interactions significantly influence decisions inferred through current model types, and thus the relevance of developing more comprehensive jurisdictional models.

To address these gaps in the literature, we developed a national HIV epidemic compartmental simulation model representative of the U.S. population and composed of 96 jurisdictions. These jurisdictions represent $54 \mathrm{EHE}$ jurisdictions (47 counties and 7 states) and 42 non-EHE jurisdictions (remaining 42 states) (Table A1 in Appendix). We did not model 3 of the 50 EHE counties stated in the EHE plan and 1 non-EHE state due to data unavailability (see Table A1 in Appendix). Within each jurisdiction, the population was further split into risk-groups (heterosexual females (HF), heterosexual males (HM), and MSM) and age-groups (individuals from ages 13 to 100). We utilized data from the National HIV Surveillance Systems (NHSS) and related studies [27], the largest nationally representative surveillance systems in the U.S., to model jurisdictional-heterogeneity in risk group distribution, HIV prevalence, care continuum distribution, and PrEP coverage $[19,28]$. As granular distributions of care continuum and sexual behavioral data by age, risk-group, and jurisdictions were not available, we made simplified assumptions suitable for the scope of this study (to understand the significance of jurisdictional-heterogeneity in the presence of 
jurisdictional-mixing). We simulated interactions between jurisdictions using varying assumptions for partnership mixing to evaluate its sensitivity on the model's outcomes.

We used the simulation model to evaluate the following: 1) the sensitivity of jurisdictional-mixing on the national HIV incidence estimates considering current jurisdictional-heterogeneity in care (care-continuum and PrEP coverage), i.e., would incidence estimates from the model change based on jurisdictional-mixing assumptions, and would they be different when using aggregated national-level care data (as in national-level models) versus jurisdiction-specific data (as in independent jurisdictional models); 2) the sensitivity of jurisdictional-mixing on the projected national HIV incidence estimates when simulating the EHE plan (diagnose, treat, prevent), i.e., if the EHE care-continuum and PrEP targets were reached by 2025 in EHE-jurisdictions and by 2030 for all other jurisdictions, would the corresponding incidence estimates vary based on mixing assumptions; and 3) the sensitivity of jurisdictional-mixing on the intervention decisions inferred through simulated estimates, i.e., would model outcomes for HIV-testing frequency and retention-in-care to achieve the EHE plan's targets vary based on jurisdictional-mixing assumptions.

Understanding the significance of jurisdictional-heterogeneity and mixing through this sensitivity analyses could help streamline data collection, and subsequently inform model development. A model that can evaluate the national epidemic as a whole, with geographical heterogeneity in population demographics, HIV epidemic, and interventions, would help identify what jurisdiction-specific strategies to adopt, such as how often to test, what should be the aim for retention-in-care, and what should be the target for PrEP coverage to achieve the intended goals of the EHE plan.

\section{Methods}

\subsection{Compartmental model}

We developed a compartmental simulation model of HIV stratified into three sexual risk-groups (HF, HM, MSM), eighty-eight age groups (individual ages from 13 to 100), four care continuum stages (Unaware, Aware no ART, ART no VLS, ART VLS), and five disease progression stages (Acute, CD4 > 500, CD4 350-500, CD4 200-350, CD4 <200). The flow diagram for care continuum transitions and disease stage progressions can be seen in Figure 1. We only simulated sexually transmitted cases of HIV and did not model transmission through injecting drug use. We developed two models, an aggregate National-Model, i.e., without geographical split (resulting in a total of $3 \times 88 \times 4$ $X 5$ compartments), and a Jurisdictional-Model, where the national population was further split into 96 geographical jurisdictions (resulting in a total of $3 \times 88 \times 4 \times 5 \times 96$ compartments) as follows:

1) National-Model: The main purpose of the National-Model was, first, for calibration of sexual behavioral parameters specific to risk-group and age-group, as data were more widely available at the national-level, and second, as a comparison against the Jurisdictional-Model to evaluate the sensitivity of jurisdictional-heterogeneity and mixing. We briefly discuss the model here and present the data used for model calibration in the Appendix. We initialized the National-Model to the 2010 HIV epidemic, using data from the NHSS [27] to distribute the population into the different compartments, and simulated the model for the period 2011 to 2018 . We simulated using differential equations as typically done in compartmental modeling (see Appendix section A1).

We estimated incidence using a Bernoulli transmission equation (see Appendix section A2) set as a function of behavior, distribution of PWH by care continuum and disease stage and corresponding HIV transmission risk, and PrEP coverage among susceptible population and corresponding HIV acquisition risk. For behavioral data, we used information from the literature for age-group and risk-group specific partnership mixing, number of partners, proportion of partnership type, number and type of sexual acts per partner (anal or vaginal), and condom use and 
effectiveness (see data in Appendix Tables A5-A11). We used simulated data for the distribution of PWH by care continuum and disease stage. We used NHSS data for PrEP coverage among susceptible persons [27]. Note, PrEP coverage was simulated for only 2017 and 2018 as PrEP was only recently initiated in the U.S., and data were available for only this period. We used data from the literature for HIV transmission risk by care continuum and disease stage of HIV infected persons, and HIV acquisition risk by PrEP-status of susceptibles (see data in Appendix Table A12). Using the data ranges from the literature, we calibrated the per act probability of transmission, age-group and sexual mixing, and average number of sexual acts per partner by fitting simulated incidence to the surveillance estimates of incidence over the period 2011 to 2018 (see data in Appendix Tables A13, A5, A6, and A9).

For the rates of transitioning across disease stages (acute, and CD4-count stages) we used data from the literature (see Table A2 Appendix). For simulating the transitioning between the care continuum stages, we used data from the literature for rate of achieving VLS when on ART and for rate of re-entry-to-care after dropping out, and data from the NHSS for the proportion linkage to care at diagnosis (see Table A2 in Appendix).

The remaining two care continuum transition parameters, i.e., rates of HIV-diagnosis and care-drop-out, are dependent on testing and retention-in-care interventions, which are likely to change over time. Thus, we estimated these rates in the simulation by fitting to the annual NHSS data on care continuum distributions (see estimation method in section A3 in Appendix).

2) Jurisdictional-Model: In this model, we further split the population into 96 jurisdictions using census data for the overall population sizes [29], NHSS data for HIV population by age, risk-group and care-continuum stage [27], and estimates from the literature for the proportion of MSM among adult males [26] (see data in Table A14 in Appendix), using jurisdiction-specific data when available. We did not model jurisdictions that did not have prevalence data, i.e., where data was either unavailable or suppressed (see Table A1 in Appendix for the list of jurisdictions modeled and excluded).

As HIV surveillance data by jurisdiction were only available for 2017, 2018, and 2019 at the time of this study, we initialized the Jurisdiction-Model to 2017. As data for care continuum distributions specific to risk-group within each jurisdiction were not available, we assumed that the ratio of risk-group specific metric to overall population metric observed at the national-level would be the same as the ratio at the jurisdictional-level. Specifically, we applied this simplified assumption to two metrics within each jurisdiction, proportion aware and proportion with ART VLS (see section A4 in Appendix). We normalized the values to ensure the sum of the proportions across all care continuum stages (Unaware, Aware no ART, ART no VLS, ART VLS) is equal to 1 for each jurisdiction.

We estimated incidence rates using a Bernoulli transmission equation, using the same behavioral data (including the calibrated values) as in the National-Model for every jurisdiction, except that we also modeled interactions between jurisdictions by using a jurisdictional-mixing matrix, and used jurisdiction-specific simulated data for care continuum stages among infected persons. We evaluated the sensitivity of jurisdictional variations in access to PrEP by implementing scenarios that used the national PrEP coverage for every jurisdiction and jurisdiction-specific PrEP coverage. To test the sensitivity of jurisdictional-mixing, we evaluated scenarios with varying levels of mixing, using data from behavioral surveys and phylogenetic studies [20-25] to set the range of values. We discuss these scenarios under Scenarios modeled.

For the natural rates of progression across disease stages (acute, and CD4-count stages) we used the same literature data as in the National-Model. For simulating the transitioning between the care continuum stages, we used the 
same data as that in the National-Model for the rate of achieving VLS when on ART and re-entry-to-care after dropping out.

The remaining two care continuum transition parameters, i.e., rates of HIV-diagnosis and care-drop-out, are related to testing and retention-in-care interventions, and thus, likely to vary across jurisdictions and over time. Thus, we evaluated multiple scenarios to test the sensitivity of jurisdictional variations. We evaluated scenarios that applied the same rates estimated by the National-Model to every jurisdiction (jurisdictional-homogeneity). We also evaluated scenarios that estimated rates by fitting to jurisdiction-specific NHSS data on care continuum distributions (jurisdictional-heterogeneity) [27] using the same method as in the National-Model (described in Appendix Section A3). These scenarios are described in more detail under Scenarios modeled.

\section{Scenarios Modeled}

We used the Jurisdictional-Model to simulate the HIV epidemic for the period 2018 to 2030. The time-unit in the model was monthly. We evaluated 16 scenarios to analyze the sensitivity of jurisdictional-heterogeneity in care continuum and the sensitivity of jurisdictional-mixing. Details of each scenario are discussed below and summarized in Table 1a, their broad differences are as follows. Scenarios S1 to S8 assumed homogeneity in care across jurisdictions by using national-level estimates for HIV-diagnosis rate, care-drop-out rate, and PrEP coverage for every jurisdiction, and homogeneity in risk-group distribution by assuming national-level estimates for the proportion of the population who are MSM [26]. On the other hand, scenarios S9 to S16 assumed heterogeneity in care across jurisdictions by estimating jurisdiction-specific HIV-diagnosis rate, care-drop-out rate, and PrEP coverage, and heterogeneity in risk-group distribution by using jurisdiction-specific estimates for proportion MSM [26]. Scenarios S1 to S4 and S9 to S12 assumed continuation of status-quo interventions by using baseline year (2018) estimates for HIV-diagnosis rate, care-drop-out rate, and PrEP coverage, and keeping it constant over the period 2019 to 2030. Scenarios S5 to S8 and S13 to S16 modeled the EHE plan by using time-varying values for HIV-diagnosis rate, caredrop-out rate, and PrEP coverage, estimated to reach the EHE targets (95-95-95 care targets and 50\% PrEP coverage among eligible) by 2025 for EHE jurisdictions and by 2030 for non-EHE jurisdictions. Scenarios S1, S5, S9, and S13 assumed no-mixing between jurisdictions, Scenarios S2, S6, S10, and S14 assumed lower levels of mixing between jurisdictions within the same state but no-mixing outside state (Level-1-mixing), Scenarios S3, S7, S11, and S15 assumed higher levels of mixing between jurisdictions within the same state but no-mixing outside state (Level-2mixing), and Scenarios S4, S8, S12, and S16 assumed higher levels of mixing between jurisdictions within the same state and mixing outside state (Level-3-mixing).

\subsection{Jurisdictional-mixing assumptions}

As noted above, we evaluated no-mixing and three types of mixing scenarios. Data for partnership mixing between persons of different jurisdictions are limited, and national-level survey data are unavailable. However, recent phylogenetic studies, which used nucleotide sequence data of persons with recent HIV diagnoses in the U.S., which infer close transmissions by creating pairwise links between persons with closely related viral DNA sequence, serve as a suitable source [25]. It must be noted that links formed through nucleotide sequencing do not necessarily indicate direct transmissions (i.e., direct partnership links) and are generated using data from only positive persons with recent diagnoses. However, as these studies are conducted at the national-level, they serve as suitable reference points for informing the sensitivity analyses in our study.

To inform the range of values for our sensitivity analyses, we used the following sources, which included surveys and phylogenetic studies. Results from a survey of Baltimore heterosexual males presented in study [20] suggest that 
almost $50 \%$ of the participants chose partners in the same or adjacent census tract. Another survey presented in study [21] about young black MSM between ages 16 to 24, states that $20 \%$ of the cases reported travelling to another region or outside the state of Mississippi. Study [24] which conducted interviews with MSM from Toronto, Canada, states that $30 \%$ of the study's participants had sex with partners outside of their town. Study of phylogenetic analysis of HIV sequences in Shanghai [23] states that 33.8\% of the HIV sequences analyzed were associated to infected individuals from another province. Phylogenetic study in [25], which used nucleotide sequence data of persons with recent HIV diagnoses across the U.S. to identify proportion of pairs with closely related sequences that were between persons of different jurisdictions, was the most comprehensive nationally representative study of the U.S population. This study also provides the most comprehensive information by presenting data specific to risk groups and jurisdiction types (within county, within state, and outside state). Data from this study showed that about $47-65 \%$ of links were between persons of same county, about $78-88 \%$ between persons of same state, and the remaining between persons of different states [25], the range corresponds to the differences across risk groups. Because links do not represent direct transmissions, they do not represent partnership links.

For data inferred through phylogenetic analyses it is infeasible to determine the time period of mixing. Data reported in behavioral surveys were from partnerships reported over a period of 12 months. Therefore, we used these data to model the proportion of annual partnerships that are with persons outside their jurisdiction. We used data from [25], which is the most comprehensive and nationally representative, to inform two sets of scenarios. Further, as mixing is likely to vary by jurisdiction and the reported proportions mixing outside jurisdiction in all the above studies were on the higher end, to the test the sensitivity of this parameter, we evaluated one additional scenario using lower values of $90-85 \%$, which is below the lowest observed in the behavioral survey studies. The scenarios are explained in more detail below and the mixing assumptions are summarized in Table $1 \mathrm{~b}$.

1. No-mixing (S1, S5, S9, and S13 in Table 1a): For these scenarios we assumed partnership mixing was $100 \%$ within jurisdiction, and $0 \%$ outside jurisdiction.

2. Level-1-mixing (S2, S6, S10, and S14 in Table 1a): For these scenarios we assumed persons in a jurisdiction could have partnerships with persons in other jurisdictions within the same state but not with persons in other states. If the jurisdiction modeled is an EHE county or a non-EHE state with EHE counties within it, we used the following for proportion mixing-within-jurisdiction: $90 \%$ for $\mathrm{HM}$ and HF, and $85 \%$ for MSM (Table 1b). For the proportion mixing with the other jurisdictions within the state we used 1 minus mixing-within-jurisdiction. If there are multiple EHE counties within a state, we split the value (1 minus mixing-within-jurisdiction) equally between the other EHE jurisdictions and the rest of the state. If the jurisdiction modeled is a state with no EHE counties within it, we assumed $100 \%$ mix within their state.

3. Level-2-mixing (S3, S7, S11, and S15 in Table 1a): For these scenarios, as above, we assumed persons in a jurisdiction could have partnerships with persons in other jurisdictions within the same state but not with persons in other states but assumed higher levels of outside mixing. If the jurisdiction modeled is an EHE county or a non-EHE state with EHE counties within it, we used the following data from [25] for the proportion mixing-within-jurisdiction: $57 \%$ for $\mathrm{HM}, 65 \%$ for HF, and $47 \%$ for MSM (Table 1b). For the proportion mixing with the other jurisdictions within the state we used 1 minus mixing-within-jurisdiction. If there are multiple EHE counties within a state, we split the value (1 minus mixing-within-jurisdiction) equally between the other EHE jurisdictions and the rest of the state. If the jurisdiction modeled is a state with no EHE counties within it, we assumed $100 \%$ mix within their state.

4. Level-3-mixing (S4, S8, S12, and S16 in Table 1a): For these scenarios we assumed persons in a jurisdiction could have partnership with persons in any jurisdiction. If the jurisdiction modeled is an EHE county or a non-EHE state with EHE counties within it, we used the following data from [25] for the proportion mixing-within-jurisdiction: $57 \%$ for HM, 
$65 \%$ for HF, and $47 \%$ for MSM (Table $1 \mathrm{~b}$ ). We used mixing-within-state minus mixing-within-jurisdiction data for the proportion mixing within state but outside their own jurisdiction ( $28 \%$ for $\mathrm{HM}, 23 \%$ for $\mathrm{HF}$, and $31 \%$ for MSM), and distributed it equally among the jurisdictions within state. We used 1 minus mixing-within-state for mixing-outsidestate and distributed it across all other states weighted by distance to the state. If the jurisdiction modeled is a state without EHE counties within it, we used mixing-within-state data from [25] for mixing within jurisdiction and distributed the remaining across all other states weighting by the distance to that state. We used the Euclidean distance between the geographical co-ordinates (latitude and longitude) of two states as a proxy for the distance between jurisdictions.

These data are summarized in Table $1 \mathrm{a}$ and $1 \mathrm{~b}$.

\subsection{Evaluating sensitivity of jurisdictional-mixing while keeping jurisdictional-homogeneity in care}

We used the Jurisdictional-Model to evaluate the sensitivity of jurisdictional-mixing when assuming jurisdictionalhomogeneity in care. Both when keeping interventions at baseline, i.e., HIV-diagnosis rate, care-drop-out rate, and PrEP coverage constant over the period 2018 to 2030 at 2018 baseline values (S1, S2, S3, and S4), and when scalingup interventions over time to meet the 95-95-95 care and 50\% PrEP targets (S5, S6, S7, and S8). To model jurisdictional-homogeneity in care, we initialized the care continuum distribution of each jurisdiction to be equal to the national-level for year 2017 year-end. We explain these scenarios in more detail below.

1. Baseline-intervention; jurisdictional-homogeneity in care (S1, $\mathbf{S 2}, \mathbf{S 3}$, and $\mathbf{S 4}$ in Table $1 \mathrm{a})$ : In these scenarios, we used the baseline estimates derived by the National-model for rates of HIV-diagnosis and care-drop-out, fitted to the national care continuum distribution in 2018. We kept these rates constant for the following years (i.e., 2019 to 2030) and used the same rates for all jurisdictions. We also kept PrEP-coverage constant at 2018 national-level for all years and all jurisdictions. While we used jurisdiction-specific data for PWH in each risk group, we assumed that the proportion of the population who are MSM is the same for every jurisdiction and used national-level estimates from [26].

2. EHE-plan-intervention; jurisdictional-homogeneity in care (S5, S6, S7, and S8 in Table 1a): In these scenarios, we used national-level estimates for the scale-up in interventions (HIV-diagnosis rate, care-drop-out rate, and PrEP coverage) to meet the EHE targets. Specifically, we used the National-Model to estimate the HIV-diagnosis rate, caredrop-out rate, and PrEP coverage necessary to linearly scale-up care continuum proportions and PrEP coverage from its national baseline values in year 2018 to the EHE targets. For EHE jurisdictions, the interventions were linearly scaled over the period 2019 to 2025 and kept constant thereafter, and for the non-EHE jurisdictions, the values were kept constant for the period 2018 to 2025 and linearly scaled-up over the period 2026 to 2030 . To recollect, the EHE targets were 95-95-95 for the care continuum and 50\% for PrEP coverage among those eligible. In the U.S., PrEP eligibility is based on specific indicators, such as a person's risk factor for acquiring HIV and recency in other sexually transmitted infections [30]. In the model, we do not simulate these PrEP indicators, thus, we use the reported number for persons with PrEP indicators to determine the percentage of susceptible population who are eligible for PrEP and take $50 \%$ of that percentage as the EHE target for PrEP coverage. Thus, a 50\% coverage among those eligible would approximately be equal to $15 \%$ coverage among all susceptible.

\subsection{Evaluating sensitivity of jurisdictional-mixing and jurisdictional-heterogeneity in care}


We used the Jurisdictional-Model to evaluate the sensitivity of jurisdictional-mixing and jurisdictional-heterogeneity in care. Both when keeping HIV-diagnosis rate, care-drop-out rate, and PrEP coverage constant over the period 2018 to 2030 (Scenarios S9, S10, S11, and S12), and when scaling-up over time to meet the 95-95-95 targets (Scenarios S13, S14, S15, and S16). To model jurisdictional-heterogeneity in care, we initialized the model to jurisdiction-specific care data for 2017 year-end and estimated jurisdiction-specific HIV-diagnosis rates, care-drop-out rates, and PrEPcoverage for the period 2019 to 2030 . We explain these scenarios in more detail below.

1. Baseline-intervention; jurisdiction-heterogeneity in care (S9, S10, S11, and $\mathbf{S 1 2}$ in Table 1a): In these scenarios, we used the jurisdiction-specific estimates for HIV-diagnosis rate, care-drop-out rate, and PrEP coverage. We derived jurisdiction-specific HIV-diagnosis rate and care-drop-out rate in the Jurisdictional-Model by using the 2018 jurisdiction-specific care continuum distributions and kept it constant for the period 2019 to 2030 . We also used 2018 jurisdiction-specific estimates of PrEP coverage and kept it constant for the period 2019 to 2030.

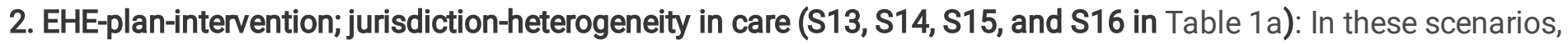
we used jurisdiction-specific estimates for the scale-up in interventions (HIV-diagnosis rate, care-drop-out rate, and PrEP coverage) to meet the EHE targets. Specifically, we used the Jurisdictional-Model to estimate jurisdictionspecific HIV-diagnosis rate, care-drop-out rate, and PrEP coverage necessary to linearly scale-up care continuum proportions and PrEP coverage from its jurisdiction-specific baseline values in year 2018 to the EHE target values and years. That is, for EHE jurisdictions, the interventions were linearly scaled over the period 2019 to 2025 and kept constant thereafter, and for the non-EHE jurisdictions, the values were kept constant for the period 2019 to 2025 and linearly scaled-up over the period 2026 to 2030. To recollect, the EHE targets were 95-95-95 for the care continuum and $50 \%$ for PrEP coverage among those eligible. PrEP eligibility was determined in the same manner as described above for EHE-plan-intervention; jurisdictional-homogeneity scenarios (S5, S6, S7, and S8).

\section{Model Verification And Output Metrics}

As the sexual behavioral parameters in the National-Model were calibrated to the national incidence between 2011 and 2018, and because these parameters were then used in the Jurisdictional-Model, we first verified that the annual risk-group specific incidence simulated by the National-Model compares well with NHSS estimates for years 2011 to 2018 (Figure 2).

Results suggest overall good fit to NHSS incidence for all three risk-groups.

For each of the 16 scenarios simulated in the Jurisdictional-Model, and for each jurisdiction, we extract the following metrics for the period 2018 to 2030: incidence as number of new infections per year, prevalence as the total number of PWH in that year, HIV-testing interval as the inverse of the HIV-diagnosis rate (a proxy), and retention-in-care rates as 1 minus the care-drop-out rate. HIV-testing intervals and retention-in-care rates serve as decision metrics to inform HIV testing and retention-in-care intervention programs, and incidence and prevalence projections serve as expected outcomes from implementing those decisions. We compare these metrics across the 16 scenarios to infer the sensitivity of model outputs to jurisdictional-mixing and jurisdictional-heterogeneity in care.

\section{Results}

While the risk-specific incidence estimates from the National-Model were within the range of NHSS estimates over the period 2011 to 2018 (as mentioned in Model Verification), as expected from the design of the scenarios, the fit of incidence estimates from the Jurisdictional-Model varied by assumptions in jurisdictional-mixing and heterogeneity 
(Figure 2). Specifically, for years 2018 and 2019, risk-group specific incidence (Figure 2) and total incidence (Figure 3) estimated by the Jurisdictional-Model were sensitive to jurisdictional-mixing (comparing no-mixing scenarios S1, S5, S9 and S13, with Level-1-mixing scenarios S2, S6, S10, and S14, Level-2-mixing scenarios S3, S7, S11, and S15, and Level-3-mixing scenarios S4, S8, S12, and S16).

We did not attempt to calibrate behavioral data to improve the fit for each scenario as our objective is to test the sensitivity of jurisdictional-mixing and heterogeneity in care and demographics while keeping all else fixed. Further, the Jurisdictional-Model excluded some counties and states due to data suppression from small data. However, the magnitude of the estimates are close to the national ranges, providing verification that the Jurisdictional-Model, which simulated local HIV epidemics in 96 jurisdictions can collectively generate results close to the overall national estimates.

In baseline-intervention scenarios, incidence projections for the period 2018 to 2030 were sensitive to jurisdictionalmixing, both when assuming jurisdictional-homogeneity in care (S1 compared to S2, S3 and S4) and jurisdictionalheterogeneity in care (S9 compared to S10, S11, and S12) (Figure 2), but more so in the former than the latter as seen by the percent change in incidence (Table 2). Compared to S9, the aggregated national incidence in S10, S11, and S12 changed by $2-2 \%, 7-5 \%$, and $8-9 \%$, respectively, whereas, compared to $S 1$, the aggregated national incidence in S2, S3, and S4 changed by 7-11\%, 24-22\%, and 24-26\%, respectively, the range corresponding to years 2018 to 2030 (see 'All' risk-group 'National' in Table 2).

In EHE-plan-intervention scenarios, in 2018, the percent change in incidence in mixing compared to no-mixing were similar to that in baseline-intervention scenarios above, which is expected as they start at the same baseline in 2018. However, as incidence decreased over the period 2019 to 2030 from scale-up of care, the differences diminished (Figure 3, Table 3). Compared to S13, the aggregated national incidence in S14, S15, and S16 changed by $2 \%$ to $-1 \%$, $7 \%$ to $-3 \%$, and $8-1 \%$, respectively, and compared to S5, the aggregated national incidence in S6, S7, and S8 changed by $7-4 \%, 24-6 \%$, and $24-10 \%$, respectively, the range corresponding to years 2018 and 2030 (see 'All' risk-group 'National' in Table 3). While the care metrics in S13 to S16 were estimated in the Jurisdictional-model during the simulation and thus varied by scenario and jurisdiction, the care metrics in S5 to S8 were extracted from the National-model and thus were constant across scenarios and jurisdictions. Therefore, diminishing differences in both sets of scenarios suggest that, while incidence is sensitive to jurisdictional-mixing when incidence was high, as incidence decreases, the sensitivity of mixing diminishes.

The differences in aggregated national incidence estimates between no-mixing and different levels of mixing assumptions observed in year 2018 (Figure 3, Tables 2 and 3) predominantly resulted from the non-EHE jurisdictions (see Figure 4, summarized in Tables 2 and 3). When assuming jurisdictional-homogeneity in care, compared to nomixing S1, incidence in S2, S3, and S4 changed by $19-28 \%, 67-55 \%$, and $60-60 \%$, respectively, for non-EHE jurisdictions (see 'All' risk-group "Non-EHE" in Table 2), whereas, it changed by $-3 \%$ to $-4 \%,-10 \%$ to $-8 \%$, and $-5 \%$ to $-4 \%$, respectively, for EHE jurisdictions (see 'All' risk-group "EHE” in Table 2), the range corresponding to years 2018 to 2030. Similarly, when assuming jurisdictional-heterogeneity in care, compared to no-mixing S9, incidence in S10, S11, and S12 changed by 5-7\%, 18-15\%, and 19-21\%, respectively, for non-EHE jurisdictions (see 'All' risk-group "NonEHE" in Table 2), whereas it changed by $-1 \%$ to $-1 \%,-2 \%$ to $-2 \%$, and $0-0 \%$, respectively, for EHE jurisdictions (see 'All' risk-group "EHE” in Table 2).

In baseline year, 2018, though overall differences in incidence between mixing assumptions were minimal when assuming heterogeneity in care, i.e., differences between scenarios S9 to S12 (Table 2) were minimal and between S13 to S16 were minimal (Table 3), the differences at the individual jurisdictions varied over a wide range. Taking 
differences in incidence within each jurisdiction, compared to S13, incidence in S14, S15, and S16 changed by -8$30 \%,-31-109 \%$, and $-27-94 \%$, respectively, the range corresponds to data across individual jurisdictions (see 'All' risk-group "National" in Table 4). Further, taking only EHE jurisdictions, compared to S13, incidence in S14, S15, and S16, changed by $-8-11 \%,-31-39 \%$, and $-27-46 \%$, respectively (see 'All' risk-group "EHE" Table 4 and Figure 5a). Considering only non-EHE jurisdictions, compared to Scenario 13, incidence in S14, S15, and S16, changed by -530\%, -18-109\%, and -11-94\%, respectively (see 'All' risk-group "Non-EHE" in Table 4, and Figure 5b). Differences in risk-group specific incidences for S13 compared to S14, S15, and S16, for EHE and non-EHE jurisdictions had similar observations as above (Table 4, and Figures A2a and A2b for HM, A3a and A3b for HF, and A4a and A4b for MSM in Appendix). Scenarios S9 to S12 would have same observations as above for year 2018, as they start at the same baseline values as S13 to S16, respectively.

A consequence of the differences in the jurisdictional-level incidence estimates is that the jurisdiction-level decisions inferred from the model would vary based on our mixing assumption. We summarize HIV-test intervals across jurisdictions into two cohorts: interval $<2$ years, and interval between $2-4$ years (Table 5 ). When test interval was $<2$ years, compared to S13, test intervals in S14, S15, and S16, changed by $-23-15 \%,-44-53 \%$, and $-45-48 \%$, respectively, the range corresponding to the minimum and maximum changes over all years, risk-groups, and jurisdictions (see 'All' risk group "National” in Table 5). Representing these in test intervals, suppose S13 on average suggests testing every 1 year, S14, S15, and S16, would suggest testing every 0.8 to 1.2 years, 0.6 to 1.5 years, and 0.6 to 1.5 years, respectively. When test interval was 2-4 years, compared to S13, test intervals in S14, S15, and S16, changed by $-14-15 \%,-33-60 \%$, and $-28-37 \%$, respectively, the range is the minimum and maximum changes over all years, risk-groups, and jurisdictions (see 'All' risk group "National” in Table 5). Representing these in test intervals, suppose S13 on average suggests testing every 3 years, S14, S15, and S16, would suggest testing every 2.6 to 3.5 years, 2 to 4.8 years, and 2.2 to 4.1 years, respectively. These changes in testing intervals from changes in mixing assumptions were similar in both EHE and non-EHE jurisdictions.

The estimated levels of retention-in-care were similar across S13 to S16, and high (ranging from 93.5-100\%), suggesting the need for highly effective retention-in-care programs to achieve the EHE targets.

For EHE jurisdictions, the cumulative reduction in incidence (over the period 2018 to 2030) in EHE scenarios compared to baseline scenarios were similar across jurisdictional-mixing and jurisdictional-heterogeneity assumptions (Table 6). However, for non-EHE jurisdictions, reduction in incidence were similar across jurisdictionalheterogeneity assumptions but different across jurisdictional-mixing assumptions. In non-EHE jurisdictions, while the expected incidence reduction in no-mixing assumption was $5 \%$ when assuming jurisdictional-homogeneity in care (and 9\% when assuming jurisdictional-heterogeneity in care), the incidence reductions in level-1 mixing was 14\% (and 15\%), level-2 mixing was 24\% (and 24\%), and level-3 mixing was 23\% (and 25\%) (Table 6).

Compared to incidence in 2019, none of the EHE-plan-intervention scenarios (S5 to S8 or S9 to S12) could reduce incidence by $75 \%$ by 2025 or $90 \%$ by 2030 , as aimed for in the EHE plan. When considering jurisdictional-

heterogeneity (S9 to S12), aggregated incidence in EHE jurisdictions in 2018 were similar or higher than aggregated incidence in non-EHE jurisdictions. With intervening in EHE jurisdictions as per the EHE-plan, aggregated incidence in EHE jurisdictions significantly reduced over the period 2019 to 2025 ( 43\% in S16). Because of continuation of the baseline-intervention up to 2025 in non-EHE jurisdictions, its aggregated incidence change over the period 2019 to 2025 was minimal, its incidence surpassing that in the EHE jurisdictions by the end of 2024. Over the period 2019 to 2025 , though non-EHE jurisdictions had some reductions in incidence in scenarios with mixing ( 11\% in S16) benefiting from the interventions in EHE, incidence in EHE jurisdictions increased because of the mixing, thus negating the overall benefits. As a result, by the end of 2025, the reduction in national aggregated reduction in 
incidence was 28\% (in S16). The reduction in national aggregated incidence by 2030 compared to 2019 was about $58 \%$ (in S16). Note that the EHE plan is to first focus on only EHE jurisdictions for the first phase (2019 to 2025) and then non-EHE jurisdictions in second phase (2025 to 2030), i.e., scaling-up interventions over period 2019 to 2030 for EHE jurisdictions and period 2025 to 2030 for non-EHE jurisdictions. Instead, if we scale-up interventions over period 2019 to 2025 in all jurisdictions, both EHE and non-EHE, and keep it constant thereafter up to 2030, we would achieve a reduction in national incidence of about $52 \%$ by 2025 and $67 \%$ by 2030 (see Figure A5 in Appendix).

The corresponding changes in prevalence (number of people with HIV) estimates over the period 2017 to 2030 are presented in Figure 6 along with the national surveillance estimates ('NHSS-National') for years 2017-2019 and sum of the 96 jurisdictions for 2017 ('NHSS-Sum of jurisdictions'). Simulated estimates of prevalence match close to the surveillance estimates for years 2017 to 2019, however, following from the changes in incidence over time (Figure 2), prevalence were most sensitive to jurisdictional-mixing in Scenarios S1 to S4 which assumed homogeneity in care and baseline interventions.

\section{Conclusions}

In this study, we developed a compartmental model to project the national HIV epidemic in the U.S. We first developed a National-Model, which calibrated risk-group and age-group specific sexual behavioral parameters at the national-level for years 2011-2018. The National-model was not split into individual jurisdictions. We then developed a Jurisdictional-Model, which split the population into 96 jurisdictions, and simulated the national HIV epidemic in the U.S. from 2018-2030 as a composition of 96 local epidemics. We used the Jurisdictional-Model to evaluate the sensitivity of jurisdictional-mixing and jurisdictional-heterogeneity in care on aggregated-national and jurisdictionspecific HIV incidence estimates, and the corresponding intervention decisions, such as HIV-testing interval and retention-in-care, inferred from the model.

We believe this is the first model that simulates the U.S. national HIV epidemic through simulating interacting individual sub-geographical jurisdictions. Our results suggest that incidence and PWH estimates are sensitive to jurisdictional-mixing and jurisdictional-heterogeneity assumptions, more so in earlier years when incidence was high. Nationally aggregated incidence were more sensitive to jurisdictional-mixing when assuming jurisdictionalhomogeneity in care than when assuming jurisdictional-heterogeneity in care. Incidence aggregated over non-EHE jurisdictions were more sensitive to jurisdictional-mixing assumptions than incidence aggregated over EHE jurisdictions. However, within each jurisdiction, incidence estimates in both EHE and non-EHE jurisdictions were sensitive to jurisdictional-mixing assumptions irrespective of jurisdictional-homogeneity or heterogeneity in care. As a consequence, jurisdictional-level decisions related to HIV-testing intervals, inferred from the model to reach the EHE targets, were sensitive to jurisdictional-mixing and jurisdictional-heterogeneity assumptions. Comparing across jurisdictional-mixing assumptions, compared to the no-mixing scenario, while there were differences in HIV-test intervals even at the lowest mixing-level, the differences were more predominant in the higher-mixing scenarios. These results suggest that when modeling jurisdictions independently, understanding the magnitude and accounting for the mixing outside jurisdiction could lead to better decisions.

Our model has limitations. Our model only simulates sexual partnership and does not model transmission due to injecting drug use. Jurisdiction-specific data on care or mixing are not fully available, and thus, our model is currently limited to be used as a tool to evaluate its sensitivity to model-inferred decisions. Sexual partnership mixing within and outside jurisdictions are likely influenced by several factors including individual preferences and social conditions [20-24], and thus vary by jurisdiction, which we did not model. We assumed there are no change in behavioral, demographic, and disease transmission factors over time.

Page $12 / 26$ 
Despite these limitations, we believe findings from this study can be used to inform model development. Our results show that though the aggregated national incidence estimates were not always sensitive to jurisdictional-mixing, within each jurisdiction, incidence estimates and corresponding model-inferred decisions were sensitive, for both EHE and non-EHE jurisdictions. Therefore, in developing jurisdiction-specific models, accounting for outside mixing can help improve model-based analyses. Our results also suggest that increased testing, care-retention, and PrEP as per the EHE plan may not achieve the $90 \%$ incidence reduction goal of the EHE plan by 2030 . Diagnose (through increased testing), treat (through care retention), and prevent (through PrEP), the interventions modeled in our analyses, are three of the four strategic pillars of the EHE plan. The fourth pillar is respond, through phylogenetic network cluster-based detection and response of new outbreaks. Our results suggest that use of the fourth pillar would be key to achieving the overall incidence reduction goals of the EHE.

\section{Abbreviations}

EHE - Ending the HIV epidemic

HIV - Human immunodeficiency virus

U.S. - United States

PWH - People with HIV

ART - Antiretroviral therapy treatment

PrEP - Pre-exposure prophylaxis

VLS - Viral load suppression

MSM - Men who have sex with men

HM - Heterosexual males

HF - Heterosexual females

NHSS - National HIV Surveillance Systems

DNA - Deoxyribonucleic acid

CD4 - Cluster of differentiation 4

\section{Declarations}

Ethics approval and consent to participate: All methods were carried out in accordance with relevant guidelines and regulations in the ethics approval and consent to participate tests according to the Declaration of Helsinki.

Consent for publication: Not applicable.

Availability of data and materials: The datasets used in the development of the simulation are presented in the Appendix and data generated and/or analysed during the current study are available from the corresponding author on reasonable request. 
Competing interests: The authors declare that they have no competing interests

Funding: Financial support for this study was provided by a grant from the National Institute of Allergy and Infectious Diseases of the National Institutes of Health under Award Number R01Al127236. The funding agreement ensured the authors' independence in designing the study, interpreting the data, writing, and publishing the report.

\section{Authors' contributions:}

Hanisha Tatapudi: selection of model input parameters and data gathering, coding and testing of the model, output analysis and review, manuscript preparation and review

Chaitra Gopalappa: conceived and designed the model, output analysis and review, manuscript preparation and review

Acknowledgements: We acknowledge Dr. Paul Farnham from the Centers for Disease Control and Prevention for his inputs on this work.

\section{References}

1. Clinical Info HIV.gov, “U.S. Statistics,” Jun. 02, 2021. https://www.hiv.gov/hiv-basics/overview/data-andtrends/statistics (accessed Aug. 12, 2021).

2. National Institutes of Health (NIH), "HIV Treatment." https://hivinfo.nih.gov/understanding-hiv/fact-sheets/hivtreatment-basics (accessed Aug. 12, 2021).

3. Centers for Disease Control and Prevention (CDC), “PrEP Effectiveness,” May 13, 2021. https://www.cdc.gov/hiv/basics/prep/prep-effectiveness.html (accessed Aug. 20, 2021).

4. America's HIV Epidemic Analysis Dashboard (AHEAD), "What is AHEAD?” https://ahead.hiv.gov/about (accessed Aug. 12, 2021).

5. HIV.gov, "What Is Ending the HIV Epidemic in the U.S.?," Jun. 02, 2021. https://www.hiv.gov/federalresponse/ending-the-hiv-epidemic/overview (accessed Aug. 12, 2021).

6. Centers for Disease Control and Prevention (CDC), “Ending the HIV Epidemic in the U.S. (EHE)," Sep. $07,2021$. https://www.cdc.gov/endhiv/jurisdictions.html? CDC_AA_refVal=https\%3A\%2F\%2Fwww.cdc.gov\%2Fendhiv\%2Fpriorities.html (accessed Dec. 14, 2021).

7. Clinical Info HIV.gov, “Prior National HIV/AIDS Strategies (2010-2021),” Dec. 01, 2021. https://www.hiv.gov/federal-response/national-hiv-aids-strategy/national-hiv-aids-strategies-2010-2021 (accessed Dec. 17, 2021).

8. America's HIV Epidemic Analysis Dashboard (AHEAD), "FAQs," EHE Goals: What are the 2025 goals and 2030 goals for each of the indicators? https://ahead.hiv.gov/faqs (accessed Aug. 20, 2021).

9. E. Krebs et al., "Developing a dynamic HIV transmission model for 6 U.S. cities: An evidence synthesis," PLoS ONE, vol. 14, no. 5, p. e0217559, May 2019, doi: 10.1371/journal.pone.0217559.

10. B. Nosyk et al., "Ending the Epidemic in America Will Not Happen if the Status Quo Continues: Modeled Projections for Human Immunodeficiency Virus Incidence in 6 US Cities," Clinical Infectious Diseases, vol. 69, no. 12, pp. 2195-2198, Nov. 2019, doi: 10.1093/cid/ciz1015.

11. X. Zang et al., "Development and Calibration of a Dynamic HIV Transmission Model for 6 US Cities," Med Decis Making, vol. 40, no. 1, pp. 3-16, Jan. 2020, doi: 10.1177/0272989X19889356. 
12. B. Nosyk et al., "Ending the HIV epidemic in the USA: an economic modelling study in six cities," The Lancet HIV, vol. 7, no. 7, pp. e491-e503, Jul. 2020, doi: 10.1016/S2352-3018(20)30033-3.

13. E. Krebs et al., "Ending the HIV Epidemic Among Persons Who Inject Drugs: A Cost-Effectiveness Analysis in Six US Cities," The Journal of Infectious Diseases, vol. 222, no. Supplement_5, pp. S301-S311, Sep. 2020, doi: 10.1093/infdis/jiaa130.

14. X. Zang et al., "Can the 'Ending the HIV Epidemic' initiative transition the USA towards HIV/AIDS epidemic control?," AIDS, vol. 34, no. 15, pp. 2325-2328, Dec. 2020, doi: 10.1097/QAD.0000000000002668.

15. B. Nosyk et al., "'Ending the Epidemic' Will Not Happen Without Addressing Racial/Ethnic Disparities in the United States Human Immunodeficiency Virus Epidemic," Clinical Infectious Diseases, vol. 71, no. 11, pp. 29682971, Dec. 2020, doi: 10.1093/cid/ciaa566.

16. A. M. L. Quan et al., "Improving health equity and ending the HIV epidemic in the USA: a distributional costeffectiveness analysis in six cities," The Lancet HIV, p. S2352301821001478, Aug. 2021, doi: 10.1016/S23523018(21)00147-8.

17. A. T. Fojo, M. Schnure, P. Kasaie, D. W. Dowdy, and M. Shah, "What Will It Take to End HIV in the United States?: A Comprehensive, Local-Level Modeling Study," Ann Intern Med, vol. 174, no. 11, pp. 1542-1553, Nov. 2021, doi: 10.7326/M21-1501.

18. S. N. Khatami, C. Gopalappa, and Mechanical and Industrial Engineering Department, University of Massachusetts Amherst, Amherst, MA 01003, USA, "A reinforcement learning model to inform optimal decision paths for HIV elimination," MBE, vol. 18, no. 6, pp. 7666-7684, 2021, doi: 10.3934/mbe.2021380.

19. N. Khurana et al., "Impact of Improved HIV Care and Treatment on PrEP Effectiveness in the United States, 2016-2020," JAIDS Journal of Acquired Immune Deficiency Syndromes, vol. 78, no. 4, pp. 399-405, Aug. 2018, doi: 10.1097/QAI.0000000000001707.

20. R. M. Gindi, F. Sifakis, S. G. Sherman, V. L. Towe, C. Flynn, and J. M. Zenilman, "The Geography of Heterosexual Partnerships in Baltimore City Adults," Sexually Transmitted Diseases, vol. 38, no. 4, pp. 260-266, Apr. 2011, doi: 10.1097/OLQ.0b013e3181f7d7f4.

21. A. M. Oster et al., "Demographic but not geographic insularity in HIV transmission among young black MSM," AIDS, vol. 25, no. 17, pp. 2157-2165, Nov. 2011, doi: 10.1097/QAD.0b013e32834bfde9.

22. R. J. Lubelchek, S. C. Hoehnen, A. L. Hotton, S. L. Kincaid, D. E. Barker, and A. L. French, "Transmission Clustering Among Newly Diagnosed HIV Patients in Chicago, 2008 to 2011: Using Phylogenetics to Expand Knowledge of Regional HIV Transmission Patterns," JAIDS Journal of Acquired Immune Deficiency Syndromes, vol. 68, no. 1, pp. 46-54, Jan. 2015, doi: 10.1097/QAl.0000000000000404.

23. X. Li et al., "Multiple introductions and onward transmission of HIV-1 subtype B strains in Shanghai, China," Journal of Infection, vol. 75, no. 2, pp. 160-168, Aug. 2017, doi: 10.1016/j.jinf.2017.05.009.

24. D. Gesink et al., "Conceptualizing Geosexual Archetypes: Mapping the Sexual Travels and Egocentric Sexual Networks of Gay and Bisexual Men in Toronto, Canada," Sexual Trans Dis, vol. 45, no. 6, pp. 368-373, Jun. 2018, doi: 10.1097/OLQ.0000000000000752.

25. A. R. Board et al., "Geographic Distribution of HIV Transmission Networks in the United States," JAIDS Journal of Acquired Immune Deficiency Syndromes, vol. 85, no. 3, pp. e32-e40, Nov. 2020, doi:

10.1097/QAI.0000000000002448.

26. J. A. Grey et al., "Estimating the Population Sizes of Men Who Have Sex With Men in US States and Counties Using Data From the American Community Survey," JMIR Public Health Surveill, vol. 2, no. 1, p. e14, Apr. 2016, doi: 10.2196/publichealth.5365. 
27. “NCHHSTP AtlasPlus.” https://www.cdc.gov/nchhstp/atlas/index.htm (accessed Nov. 04, 2021).

28. C. Gopalappa, P. G. Farnham, Y.-H. Chen, and S. L. Sansom, "Progression and Transmission of HIV/AIDS (PATH 2.0): A New, Agent-Based Model to Estimate HIV Transmissions in the United States," Med Decis Making, vol. 37, no. 2, pp. 224-233, Feb. 2017, doi: 10.1177/0272989X16668509.

29. United States Census Bureau, "Annual County Resident Population Estimates by Age, Sex, Race, and Hispanic Origin: April 1, 2010 to July 1, 2019," Jun. 2020. https://www2.census.gov/programssurveys/popest/datasets/2010-2019/counties/asrh/cc-est2019-alldata.csv (accessed Nov. 04, 2021).

30. Clinical Info HIV.gov, "Recommendations for the Use of Antiretroviral Drugs in Pregnant Women with HIV Infection and Interventions to Reduce Perinatal HIV Transmission in the United States," Dec. 29, 2020. https://clinicalinfo.hiv.gov/en/guidelines/perinatal/prep (accessed Nov. 08, 2021).

\section{Tables}


Table 1

a: Scenarios simulated using the Jurisdictional-Model

\begin{tabular}{|c|c|c|c|c|}
\hline \multirow[t]{2}{*}{$\begin{array}{l}\text { Scenario } \\
\text { no. }\end{array}$} & \multirow[t]{2}{*}{$\begin{array}{l}\text { Mixing } \\
\text { assumption }\end{array}$} & \multicolumn{2}{|c|}{$\begin{array}{l}\text { Care Intervention } \\
\text { (HIV-diagnosis rate, care-drop-out rate, and PrEP coverage) }\end{array}$} & \multirow[t]{2}{*}{$\begin{array}{l}\text { Jurisdictional- } \\
\text { heterogeneity } \\
\text { assumption }\end{array}$} \\
\hline & & EHE jurisdictions & non-EHE jurisdictions & \\
\hline [S1] & No-mixing & \multirow{4}{*}{$\begin{array}{l}\text { Baseline (2018): Values kept } \\
\text { constant at } 2018 \text { national } \\
\text { estimates for all years }\end{array}$} & \multirow{4}{*}{$\begin{array}{l}\text { Baseline (2018): Values kept } \\
\text { constant at } 2018 \text { national } \\
\text { estimates for all years }\end{array}$} & \multirow{8}{*}{$\begin{array}{l}\text { Homogeneous } \\
\text { care and risk- } \\
\text { group } \\
\text { distribution: } \\
\text { national } \\
\text { estimates used } \\
\text { for all } \\
\text { jurisdictions }\end{array}$} \\
\hline [s2] & $\begin{array}{l}\text { Level 1- } \\
\text { mixing }\end{array}$ & & & \\
\hline [S3] & $\begin{array}{l}\text { Level-2 } \\
\text { mixing }\end{array}$ & & & \\
\hline [S4] & $\begin{array}{l}\text { Level-3 } \\
\text { mixing }\end{array}$ & & & \\
\hline [S5] & No-mixing & \multirow{4}{*}{$\begin{array}{l}\text { EHE plan: Values calibrated } \\
\text { to nationally achieve EHE } \\
\text { targets ( } 95-95-95) \text { by } 2025, \\
\text { and kept constant at } 2025 \\
\text { value thereafter }\end{array}$} & \multirow{4}{*}{$\begin{array}{l}\text { EHE plan: Values kept constant } \\
\text { at } 2018 \text { national estimates until } \\
2025 \text {, and thereafter, calibrated } \\
\text { to nationally achieve EHE } \\
\text { targets (95-95-95) by } 2030\end{array}$} & \\
\hline [S6] & $\begin{array}{l}\text { Level 1- } \\
\text { mixing }\end{array}$ & & & \\
\hline [S7] & $\begin{array}{l}\text { Level-2 } \\
\text { mixing }\end{array}$ & & & \\
\hline [S8] & $\begin{array}{l}\text { Level-3 } \\
\text { mixing }\end{array}$ & & & \\
\hline [S9] & No-mixing & \multirow{4}{*}{$\begin{array}{l}\text { Baseline (2018): Values kept } \\
\text { constant at 2018 jurisdiction- } \\
\text { specific for all years }\end{array}$} & \multirow{4}{*}{$\begin{array}{l}\text { Baseline (2018): Values kept } \\
\text { constant at } 2018 \text { jurisdiction- } \\
\text { specific for all years }\end{array}$} & \multirow{8}{*}{$\begin{array}{l}\text { Heterogeneous } \\
\text { care and risk- } \\
\text { group } \\
\text { distribution: } \\
\text { jurisdiction- } \\
\text { specific } \\
\text { estimates }\end{array}$} \\
\hline [S10] & $\begin{array}{l}\text { Level 1- } \\
\text { mixing }\end{array}$ & & & \\
\hline [S11] & $\begin{array}{l}\text { Level-2 } \\
\text { mixing }\end{array}$ & & & \\
\hline [S12] & $\begin{array}{l}\text { Level-3 } \\
\text { mixing }\end{array}$ & & & \\
\hline [S13] & No-mixing & \multirow{4}{*}{$\begin{array}{l}\text { EHE plan: Jurisdiction- } \\
\text { specific estimates calibrated } \\
\text { to achieve EHE targets }(95-95- \\
95) \text { within each jurisdiction } \\
\text { by } 2025 \text {, and kept constant at } \\
2025 \text { value thereafter }\end{array}$} & \multirow{2}{*}{$\begin{array}{l}\text { EHE plan: Jurisdiction-specific } \\
\text { estimates kept constant at } 2018 \\
\text { values until 2025, and } \\
\text { thereafter, calibrated to achieve }\end{array}$} & \\
\hline [S14] & $\begin{array}{l}\text { Level 1- } \\
\text { mixing }\end{array}$ & & & \\
\hline [S15] & $\begin{array}{l}\text { Level-2 } \\
\text { mixing }\end{array}$ & & $\begin{array}{l}\text { EHE targets (95-95-95) by } 2030 \\
\text { within each jurisdiction }\end{array}$ & \\
\hline [S16] & $\begin{array}{l}\text { Level-3 } \\
\text { mixing }\end{array}$ & & & \\
\hline
\end{tabular}


Table 1

b: Assumptions of sexual partnership mixing across jurisdictions

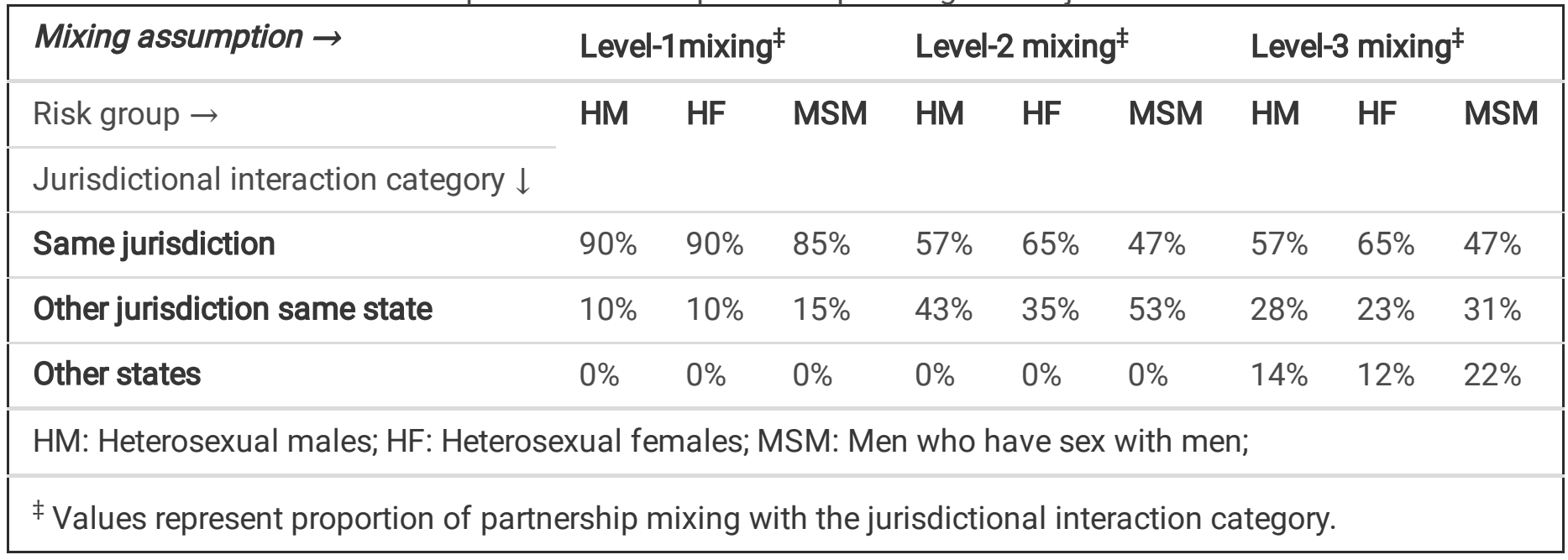


Table 2

Change in aggregated incidence ${ }^{\dagger}(2018,2030)^{\ddagger}$ in mixing scenarios compared to no-mixing (baseline intervention $\left.{ }^{\mathbb{Z}}\right)$

\begin{tabular}{|c|c|c|c|c|c|c|c|c|c|}
\hline \multicolumn{2}{|c|}{ Scenario no. $\rightarrow$} & s1 & S2 & S3 & S4 & s9 & S10 & $\mathrm{S} 11$ & $\mathrm{~S} 12$ \\
\hline \multicolumn{2}{|c|}{$\begin{array}{l}\text { Care assumption } \\
\rightarrow\end{array}$} & \multicolumn{4}{|c|}{$\begin{array}{l}\text { Homogeneity in care across jurisdictions } \\
(2018,2030) \ddagger\end{array}$} & \multicolumn{4}{|c|}{$\begin{array}{l}\text { Heterogeneity in care across jurisdictions } \\
(2018,2030) \ddagger\end{array}$} \\
\hline \multicolumn{2}{|c|}{$\underset{\rightarrow}{\text { Mixing assumption }}$} & $\begin{array}{l}\text { No- } \\
\text { mixing }\end{array}$ & $\begin{array}{l}\text { Mixing } \\
\text { level } 1\end{array}$ & $\begin{array}{l}\text { Mixing } \\
\text { level } 2\end{array}$ & $\begin{array}{l}\text { Mixing } \\
\text { level } 3\end{array}$ & $\begin{array}{l}\text { No- } \\
\text { mixing }\end{array}$ & $\begin{array}{l}\text { Mixing } \\
\text { level } 1\end{array}$ & $\begin{array}{l}\text { Mixing } \\
\text { level } 2\end{array}$ & $\begin{array}{l}\text { Mixing } \\
\text { level } 3\end{array}$ \\
\hline $\begin{array}{l}\text { Risk } \\
\text { group } \downarrow\end{array}$ & $\begin{array}{l}\text { Jur. } \\
\text { type } \downarrow\end{array}$ & & & & & & & & \\
\hline \multirow[t]{3}{*}{ All } & National & Ref & $7 \%, 11 \%$ & $\begin{array}{l}24 \% \\
22 \%\end{array}$ & $\begin{array}{l}24 \% \\
26 \%\end{array}$ & Ref & $2 \%, 2 \%$ & $7 \%, 5 \%$ & $8 \%, 9 \%$ \\
\hline & EHE & Ref & $-3 \%,-4 \%$ & $\begin{array}{l}-10 \% \\
-8 \%\end{array}$ & $-5 \%,-4 \%$ & Ref & $-1 \%,-1 \%$ & $-2 \%,-2 \%$ & $0 \%, 0 \%$ \\
\hline & $\begin{array}{l}\text { Non- } \\
\text { EHE }\end{array}$ & Ref & $\begin{array}{l}19 \% \\
28 \%\end{array}$ & $\begin{array}{l}67 \% \\
55 \%\end{array}$ & $\begin{array}{l}60 \% \\
60 \%\end{array}$ & Ref & $5 \%, 7 \%$ & $\begin{array}{l}18 \% \\
15 \%\end{array}$ & $\begin{array}{l}19 \% \\
21 \%\end{array}$ \\
\hline \multirow[t]{3}{*}{ HM } & National & Ref & $5 \%, 8 \%$ & $\begin{array}{l}22 \% \\
21 \%\end{array}$ & $\begin{array}{l}24 \% \\
25 \%\end{array}$ & Ref & $5 \%, 4 \%$ & $\begin{array}{l}21 \% \\
14 \%\end{array}$ & $\begin{array}{l}21 \% \\
16 \%\end{array}$ \\
\hline & EHE & Ref & $-2 \%,-4 \%$ & $\begin{array}{l}-9 \% \\
-10 \%\end{array}$ & $0 \%,-4 \%$ & Ref & $-2 \%,-2 \%$ & $-8 \%,-7 \%$ & $-6 \%,-6 \%$ \\
\hline & $\begin{array}{l}\text { Non- } \\
\text { EHE }\end{array}$ & Ref & $\begin{array}{l}15 \% \\
25 \%\end{array}$ & $\begin{array}{l}65 \% \\
65 \%\end{array}$ & $\begin{array}{l}57 \% \\
64 \%\end{array}$ & Ref & $\begin{array}{l}14 \% \\
11 \%\end{array}$ & $\begin{array}{l}59 \% \\
36 \%\end{array}$ & $\begin{array}{l}57 \% \\
39 \%\end{array}$ \\
\hline \multirow[t]{3}{*}{ HF } & National & Ref & $4 \%, 9 \%$ & $\begin{array}{l}15 \% \\
20 \%\end{array}$ & $\begin{array}{l}16 \% \\
23 \%\end{array}$ & Ref & $2 \%, 3 \%$ & $7 \%, 7 \%$ & $8 \%, 10 \%$ \\
\hline & EHE & Ref & $-2 \%,-4 \%$ & $-8 \%,-9 \%$ & $-5 \%,-5 \%$ & Ref & $-1 \%,-1 \%$ & $-3 \%,-3 \%$ & $-2 \%,-3 \%$ \\
\hline & $\begin{array}{l}\text { Non- } \\
\text { EHE }\end{array}$ & Ref & $\begin{array}{l}14 \% \\
26 \%\end{array}$ & $\begin{array}{l}50 \% \\
56 \%\end{array}$ & $\begin{array}{l}45 \% \\
59 \%\end{array}$ & Ref & $5 \%, 7 \%$ & $\begin{array}{l}17 \% \\
16 \%\end{array}$ & $\begin{array}{l}17 \% \\
21 \%\end{array}$ \\
\hline \multirow[t]{3}{*}{ MSM } & National & Ref & $8 \%, 12 \%$ & $\begin{array}{l}27 \% \\
22 \%\end{array}$ & $\begin{array}{l}27 \% \\
27 \%\end{array}$ & Ref & $1 \%, 2 \%$ & $5 \%, 4 \%$ & $6 \%, 9 \%$ \\
\hline & EHE & Ref & $-3 \%,-4 \%$ & $\begin{array}{l}-11 \% \\
-8 \%\end{array}$ & $-5 \%,-4 \%$ & Ref & $0 \%,-1 \%$ & $-1 \%,-2 \%$ & $1 \%, 2 \%$ \\
\hline & $\begin{array}{l}\text { Non- } \\
\text { EHE }\end{array}$ & Ref & $\begin{array}{l}20 \% \\
29 \%\end{array}$ & $\begin{array}{l}72 \%, \\
54 \%\end{array}$ & $\begin{array}{l}64 \% \\
60 \%\end{array}$ & Ref & $4 \%, 6 \%$ & $\begin{array}{l}14 \% \\
12 \%\end{array}$ & $\begin{array}{l}15 \% \\
19 \%\end{array}$ \\
\hline
\end{tabular}

HM: Heterosexual males; HF: Heterosexual females; MSM: Men who have sex with men;

National: aggregate of all EHE and non-EHE jurisdictions; EHE: aggregate of all EHE jurisdictions; Non-EHE: aggregate of all non-EHE jurisdictions;

$\dagger \%$ change in incidence in mixing compared to no-mixing scenario $=100 \times($ mixing scenario - no-mixing scenario)/mixing scenario).

‡ Values presented are for years 2018, 2030, respectively, and represents the range over the duration of the simulation.

${ }^{\mathbb{S}}$ Scenarios 1 to 4 and 9 to 12 keep care metrics (HIV-diagnosis rate, care-drop-out rate, and PrEP coverage) fixed at the 2018 baseline values for the full duration of the simulation. 
Table 3

Change in aggregated incidence ${ }^{\dagger}(2018,2030)^{\ddagger}$ in mixing scenarios compared to no-mixing (EHE plan ${ }^{\mathbb{}}$ )

\begin{tabular}{|c|c|c|c|c|c|c|c|c|c|}
\hline \multirow{2}{*}{\multicolumn{2}{|c|}{$\begin{array}{l}\text { Scenario no. } \rightarrow \\
\text { Care assumption } \rightarrow\end{array}$}} & S5 & s6 & S7 & S8 & $\mathrm{S} 13$ & S14 & $\mathrm{S} 15$ & $\mathrm{~s} 16$ \\
\hline & nption $\rightarrow$ & \multicolumn{4}{|c|}{$\begin{array}{l}\text { Homogeneity in } \\
(2018,2030)^{\ddagger}\end{array}$} & \multicolumn{4}{|c|}{$\begin{array}{l}\text { Heterogeneity i } \\
(2018,2030)^{\ddagger}\end{array}$} \\
\hline \multicolumn{2}{|c|}{$\underset{\rightarrow}{\text { Mixing assumption }}$} & $\begin{array}{l}\text { No- } \\
\text { mixing }\end{array}$ & $\begin{array}{l}\text { Mixing } \\
\text { level } 1\end{array}$ & $\begin{array}{l}\text { Mixing } \\
\text { level } 2\end{array}$ & $\begin{array}{l}\text { Mixing } \\
\text { level } 3\end{array}$ & $\begin{array}{l}\text { No- } \\
\text { mixing }\end{array}$ & $\begin{array}{l}\text { Mixing } \\
\text { level } 1\end{array}$ & $\begin{array}{l}\text { Mixing } \\
\text { level } 2\end{array}$ & $\begin{array}{l}\text { Mixing } \\
\text { level } 3\end{array}$ \\
\hline $\begin{array}{l}\text { Risk } \\
\text { group } \downarrow\end{array}$ & $\begin{array}{l}\text { Jur. } \\
\text { type } \downarrow\end{array}$ & & & & & & & & \\
\hline \multirow[t]{3}{*}{ All } & National & Ref & $7 \%, 4 \%$ & $24 \%, 6 \%$ & $\begin{array}{l}24 \% \\
10 \%\end{array}$ & Ref & $2 \%,-1 \%$ & $7 \%,-3 \%$ & $8 \%, 1 \%$ \\
\hline & EHE & Ref & $-3 \%, 0 \%$ & $\begin{array}{l}-10 \% \\
1 \%\end{array}$ & $-5 \%, 7 \%$ & Ref & $-1 \%, 4 \%$ & $-2 \%, 8 \%$ & $0 \%, 15 \%$ \\
\hline & $\begin{array}{l}\text { Non- } \\
\text { EHE }\end{array}$ & Ref & $19 \%, 7 \%$ & $67 \%, 9 \%$ & $\begin{array}{l}60 \% \\
13 \%\end{array}$ & Ref & $5 \%,-4 \%$ & $\begin{array}{l}18 \% \\
-11 \%\end{array}$ & $19 \%,-9 \%$ \\
\hline \multirow[t]{3}{*}{$\mathrm{HM}$} & National & Ref & $5 \%, 4 \%$ & $\begin{array}{l}22 \% \\
10 \%\end{array}$ & $\begin{array}{l}23 \% \\
13 \%\end{array}$ & Ref & $5 \%, 0 \%$ & $21 \%, 0 \%$ & $21 \%, 5 \%$ \\
\hline & EHE & Ref & $-2 \%,-2 \%$ & $-9 \%,-4 \%$ & $-6 \%, 0 \%$ & Ref & $-2 \%, 0 \%$ & $-8 \%,-25$ & $-6 \%, 2 \%$ \\
\hline & $\begin{array}{l}\text { Non- } \\
\text { EHE }\end{array}$ & Ref & $15 \%, 9 \%$ & $\begin{array}{l}65 \% \\
21 \%\end{array}$ & $\begin{array}{l}63 \% \\
24 \%\end{array}$ & Ref & $14 \%, 0 \%$ & $59 \%, 5 \%$ & $57 \%, 6 \%$ \\
\hline \multirow[t]{3}{*}{ HF } & National & Ref & $4 \%, 4 \%$ & $15 \%, 7 \%$ & $\begin{array}{l}15 \% \\
10 \%\end{array}$ & Ref & $2 \%,-2 \%$ & $7 \%,-5 \%$ & $8 \%,-2 \%$ \\
\hline & EHE & Ref & $-2 \%,-1 \%$ & $-8 \%, 0 \%$ & $-7 \%, 4 \%$ & Ref & $-1 \%, 2 \%$ & $-3 \%, 4 \%$ & $-2 \%, 8 \%$ \\
\hline & $\begin{array}{l}\text { Non- } \\
\text { EHE }\end{array}$ & Ref & $14 \%, 7 \%$ & $\begin{array}{l}50 \% \\
11 \%\end{array}$ & $\begin{array}{l}47 \% \\
14 \%\end{array}$ & Ref & $5 \%,-3 \%$ & $17 \%,-9 \%$ & $17 \%,-7 \%$ \\
\hline \multirow[t]{3}{*}{ MSM } & National & Ref & $8 \%, 4 \%$ & $28 \%, 6 \%$ & $\begin{array}{l}26 \% \\
10 \%\end{array}$ & Ref & $1 \%,-1 \%$ & $5 \%,-3 \%$ & $6 \%, 2 \%$ \\
\hline & EHE & Ref & $-3 \%, 0 \%$ & $\begin{array}{l}-11 \%, \\
2 \%\end{array}$ & $-9 \%, 8 \%$ & Ref & $0 \%, 5 \%$ & $-1 \%, 10 \%$ & $1 \%, 18 \%$ \\
\hline & $\begin{array}{l}\text { Non- } \\
\text { EHE }\end{array}$ & Ref & $20 \%, 6 \%$ & $72 \%, 8 \%$ & $\begin{array}{l}67 \%, \\
11 \%\end{array}$ & Ref & $4 \%,-5 \%$ & $\begin{array}{l}14 \% \\
-13 \%\end{array}$ & $\begin{array}{l}15 \% \\
-11 \%\end{array}$ \\
\hline
\end{tabular}

HM: Heterosexual males; HF: Heterosexual females; MSM: Men who have sex with men;

National: aggregate of all EHE and non-EHE jurisdictions; EHE: aggregate of all EHE jurisdictions; Non-EHE: aggregate of all non-EHE jurisdictions;

$\dagger \%$ change in incidence in mixing compared to no-mixing scenario $=100 \times($ mixing scenario - no-mixing scenario)/mixing scenario).

‡ Values presented are for years 2018, 2030, respectively, and represents the range over the duration of the simulation.

\Scenarios 5 to 8 and 13 to 16 scale-up care metrics (HIV-diagnosis rate, care-drop-out rate, and PrEP coverage) from 2018 baseline to reach EHE targets by 2025 for EHE jurisdictions and by 2030 for non-EHE jurisdictions. 
Table 4

Change in jurisdiction-specific incidence ${ }^{\dagger}$ (min, max $\left.{ }^{\ddagger}\right)$ in mixing scenarios compared to no-mixing $(2018 \S$, with jurisdictional-heterogeneity ${ }^{\mathbb{Z}}$ )

\begin{tabular}{|c|c|c|c|c|c|}
\hline \multicolumn{2}{|c|}{ Scenario no. $\rightarrow$} & $\begin{array}{l}\text { s9* (or } \\
\text { s13)§ }\end{array}$ & $\begin{array}{l}\text { S10* (or } \\
\text { s14)§ }\end{array}$ & $\mathrm{S} 11^{*}$ (or S15)§ & $\mathrm{S} 12^{*}$ (or S16)§ \\
\hline \multicolumn{2}{|c|}{ Mixing assumption $\rightarrow$} & \multirow[t]{2}{*}{ No-mixing } & \multirow{2}{*}{$\begin{array}{l}\text { Mixing level } \\
(\min , \max )^{\ddagger}\end{array}$} & \multirow{2}{*}{$\begin{array}{l}\text { Mixing level } 2 \text { (min, } \\
\text { max) } \ddagger\end{array}$} & \multirow{2}{*}{$\begin{array}{l}\text { Mixing level } 3 \text { (min, } \\
\text { max) } \neq\end{array}$} \\
\hline $\begin{array}{l}\text { Risk group } \\
\downarrow\end{array}$ & $\begin{array}{l}\text { Jur. type } \\
\downarrow\end{array}$ & & & & \\
\hline \multirow[t]{3}{*}{ All } & National & Ref & $-8 \%, 30 \%$ & $-31 \%, 109 \%$ & $-27 \%, 94 \%$ \\
\hline & EHE & Ref & $-8 \%, 11 \%$ & $-31 \%, 39 \%$ & $-27 \%, 46 \%$ \\
\hline & Non-EHE & Ref & $-5 \%, 30 \%$ & $-18 \%, 109 \%$ & $-11 \%, 94 \%$ \\
\hline \multirow[t]{3}{*}{ HM } & National & Ref & $-9 \%, 63 \%$ & $-37 \%, 269 \%$ & $-31 \%, 221 \%$ \\
\hline & EHE & Ref & $-9 \%, 13 \%$ & $-37 \%, 56 \%$ & $-31 \%, 43 \%$ \\
\hline & Non-EHE & Ref & $0 \%, 63 \%$ & $0 \%, 269 \%$ & $8 \%, 221 \%$ \\
\hline \multirow[t]{3}{*}{ HF } & National & Ref & $-8 \%, 36 \%$ & $-27 \%, 125 \%$ & $-23 \%, 99 \%$ \\
\hline & EHE & Ref & $-8 \%, 9 \%$ & $-27 \%, 31 \%$ & $-23 \%, 25 \%$ \\
\hline & Non-EHE & Ref & $-4 \%, 36 \%$ & $-14 \%, 125 \%$ & $-11 \%, 99 \%$ \\
\hline \multirow[t]{3}{*}{ MSM } & National & Ref & $-9 \%, 24 \%$ & $-31 \%, 84 \%$ & $-34 \%, 71 \%$ \\
\hline & EHE & Ref & $-9 \%, 12 \%$ & $-31 \%, 44 \%$ & $-34 \%, 52 \%$ \\
\hline & Non-EHE & Ref & $-6 \%, 24 \%$ & $-22 \%, 84 \%$ & $-17 \%, 71 \%$ \\
\hline
\end{tabular}

HM: Heterosexual males; HF: Heterosexual females; MSM: Men who have sex with men;

National: aggregate of all EHE and non-EHE jurisdictions; EHE: aggregate of all EHE jurisdictions; Non-EHE: aggregate of all non-EHE jurisdictions;

${ }^{\dagger}$ Jurisdiction-specific \% change in incidence in mixing compared to no-mixing scenario $=100 \times($ mixing scenario - no-mixing scenario)/mixing scenario).

$\ddagger$ Values presented are the range (minimum, maximum) across jurisdictions for year 2018.

${ }^{\otimes}$ Scenarios S9 to S12 and Scenarios S13 to S16 assume jurisdictional-heterogeneity.

* Scenarios S9 to S12 (baseline intervention) and § Scenarios S13 to S16 (EHE plan intervention) start at same baseline using 2018 care metrics (HIV-diagnosis rate, care-drop-out rate, and PrEP coverage) 
Table 5

Percentage change in HIV-test intervals ${ }^{\dagger}$ ( $\mathrm{min}, \mathrm{max}^{\ddagger}$ ) in mixing scenarios compared to no-mixing (EHE plan)

\begin{tabular}{|c|c|c|c|c|c|c|c|c|c|c|}
\hline \multicolumn{3}{|c|}{ Year $\rightarrow$} & \multicolumn{4}{|c|}{$\begin{array}{l}\text { Mid intervention year } \\
\text { (2022 for EHE and } \\
2028 \text { for non-EHE) } \S\end{array}$} & \multicolumn{4}{|c|}{$\begin{array}{l}\text { Target year } \\
\text { (2025 for EHE and } \\
2030 \text { for non-EHE) } \S\end{array}$} \\
\hline \multicolumn{3}{|c|}{ Scenario no. $\rightarrow$} & S13 & S14 & S15 & S16 & $\mathrm{S} 13$ & S14 & S15 & S16 \\
\hline \multicolumn{3}{|c|}{ Mixing assumption $\rightarrow$} & $\begin{array}{l}\text { No- } \\
\text { mixing }\end{array}$ & $\begin{array}{l}\text { Mixing } \\
\text { level } 1\end{array}$ & $\begin{array}{l}\text { Mixing } \\
\text { level ? }\end{array}$ & $\begin{array}{l}\text { Mixing } \\
\text { level } 3\end{array}$ & $\begin{array}{l}\text { No- } \\
\text { mixing }\end{array}$ & $\begin{array}{l}\text { Mixing } \\
\text { level } 1\end{array}$ & $\begin{array}{l}\text { Mixing } \\
\text { level } 2\end{array}$ & $\begin{array}{l}\text { Mixing } \\
\text { level } 3\end{array}$ \\
\hline $\begin{array}{l}\text { Risk } \\
\text { group } \\
\downarrow\end{array}$ & $\begin{array}{l}\text { Jur. type } \\
\downarrow\end{array}$ & $\begin{array}{l}\text { Test } \\
\text { interval } \\
\downarrow\end{array}$ & & & & & & & & \\
\hline \multirow[t]{4}{*}{ MSM } & EHE & $\begin{array}{l}<2 \\
\text { years }\end{array}$ & Ref & $-14 \%, 9 \%$ & $\begin{array}{l}-32 \% \\
25 \%\end{array}$ & $\begin{array}{l}-35 \% \\
20 \%\end{array}$ & Ref & $\begin{array}{l}-23 \% \\
5 \%\end{array}$ & $\begin{array}{l}-44 \% \\
13 \%\end{array}$ & $\begin{array}{l}-45 \% \\
12 \%\end{array}$ \\
\hline & & $\begin{array}{l}2-4 \\
\text { years }\end{array}$ & Ref & $-9 \%, 10 \%$ & $\begin{array}{l}-23 \% \\
36 \%\end{array}$ & $\begin{array}{l}-20 \% \\
34 \%\end{array}$ & Ref & $\begin{array}{l}2 \% \\
10 \%\end{array}$ & $\begin{array}{l}4 \% \\
34 \%\end{array}$ & $\begin{array}{l}6 \% \\
30 \%\end{array}$ \\
\hline & $\begin{array}{l}\text { Non- } \\
\text { EHE }\end{array}$ & $\begin{array}{l}<2 \\
\text { years }\end{array}$ & Ref & $-2 \%, 15 \%$ & $\begin{array}{l}0 \% \\
53 \%\end{array}$ & $\begin{array}{l}-16 \% \\
48 \%\end{array}$ & Ref & $\begin{array}{l}-4 \%, \\
13 \%\end{array}$ & $\begin{array}{l}-7 \% \\
50 \%\end{array}$ & $\begin{array}{l}-14 \% \\
37 \%\end{array}$ \\
\hline & & $\begin{array}{l}2-4 \\
\text { years }\end{array}$ & Ref & $10 \%, 15 \%$ & $\begin{array}{l}34 \% \\
60 \%\end{array}$ & $\begin{array}{l}36 \% \\
37 \%\end{array}$ & Ref & * & * & * \\
\hline \multirow[t]{4}{*}{ HF } & EHE & $\begin{array}{l}<2 \\
\text { years }\end{array}$ & Ref & $-12 \%, 6 \%$ & $\begin{array}{l}-29 \% \\
19 \%\end{array}$ & $\begin{array}{l}-28 \% \\
21 \%\end{array}$ & Ref & $\begin{array}{l}-21 \% \\
4 \%\end{array}$ & $\begin{array}{l}-43 \% \\
11 \%\end{array}$ & $\begin{array}{l}-40 \% \\
13 \%\end{array}$ \\
\hline & & $\begin{array}{l}2-4 \\
\text { years }\end{array}$ & Ref & $-9 \%, 9 \%$ & $\begin{array}{l}-23 \% \\
35 \%\end{array}$ & $\begin{array}{l}-22 \% \\
28 \%\end{array}$ & Ref & $\begin{array}{l}-14 \% \\
8 \%\end{array}$ & $\begin{array}{l}-33 \% \\
28 \%\end{array}$ & $\begin{array}{l}-28 \% \\
28 \%\end{array}$ \\
\hline & $\begin{array}{l}\text { Non- } \\
\text { EHE }\end{array}$ & $\begin{array}{l}<2 \\
\text { years }\end{array}$ & Ref & $-3 \%, 11 \%$ & $\begin{array}{l}-3 \% \\
39 \%\end{array}$ & $\begin{array}{l}-15 \%, \\
36 \%\end{array}$ & Ref & $\begin{array}{l}-5 \%, \\
9 \%\end{array}$ & $\begin{array}{l}-11 \%, \\
30 \%\end{array}$ & $\begin{array}{l}-14 \% \\
26 \%\end{array}$ \\
\hline & & $\begin{array}{l}2-4 \\
\text { years }\end{array}$ & Ref & $-5 \%, 6 \%$ & $\begin{array}{l}-8 \%, \\
19 \%\end{array}$ & $\begin{array}{l}-14 \%, \\
18 \%\end{array}$ & Ref & $\begin{array}{l}-7 \% \\
4 \%\end{array}$ & $\begin{array}{l}-15 \% \\
12 \%\end{array}$ & $\begin{array}{l}-14 \% \\
12 \%\end{array}$ \\
\hline \multirow[t]{3}{*}{$\mathrm{HM}$} & EHE & $\begin{array}{l}<2 \\
\text { years }\end{array}$ & Ref & $-8 \%, 5 \%$ & $\begin{array}{l}-25 \% \\
22 \%\end{array}$ & $\begin{array}{l}-26 \% \\
20 \%\end{array}$ & Ref & $\begin{array}{l}-11 \%, \\
6 \%\end{array}$ & $\begin{array}{l}-27 \%, \\
31 \%\end{array}$ & $\begin{array}{l}-29 \% \\
32 \%\end{array}$ \\
\hline & & $\begin{array}{l}2-4 \\
\text { years }\end{array}$ & Ref & $-9 \%, 8 \%$ & $\begin{array}{l}-29 \% \\
36 \%\end{array}$ & $\begin{array}{l}-25 \% \\
36 \%\end{array}$ & Ref & $\begin{array}{l}-5 \% \\
7 \%\end{array}$ & $\begin{array}{l}-19 \% \\
30 \%\end{array}$ & $\begin{array}{l}-15 \% \\
33 \%\end{array}$ \\
\hline & $\begin{array}{l}\text { Non- } \\
\text { EHE }\end{array}$ & $\begin{array}{l}<2 \\
\text { years }\end{array}$ & Ref & $-3 \%, 11 \%$ & $\begin{array}{l}-7 \% \\
41 \%\end{array}$ & $\begin{array}{l}-17 \% \\
30 \%\end{array}$ & Ref & $\begin{array}{l}-12 \% \\
10 \%\end{array}$ & $\begin{array}{l}-28 \% \\
32 \%\end{array}$ & $\begin{array}{l}-26 \%, \\
23 \%\end{array}$ \\
\hline
\end{tabular}

HM: Heterosexual males; HF: Heterosexual females; MSM: Men who have sex with men;

National: aggregate of all EHE and non-EHE jurisdictions; EHE: aggregate of all EHE jurisdictions; Non-EHE: aggregate of all non-EHE jurisdictions;

† \% change in HIV-testing interval estimate in mixing scenarios compared to no-mixing scenario and calculated as $100 \times$ (mixing scenario - no-mixing scenario)/mixing scenario).

‡ Values presented are the range (minimum, maximum) across the jurisdiction type for the specific time interval cohort (i.e., < 2 years (minimum value was 6 months) or 2-4 years).

\Scenarios 13 to 16 scale-up care metrics (HIV-diagnosis rate, care-drop-out rate, and PrEP coverage) to reach EHE targets by 2025 for EHE jurisdictions and by 2030 for non-EHE jurisdictions. 


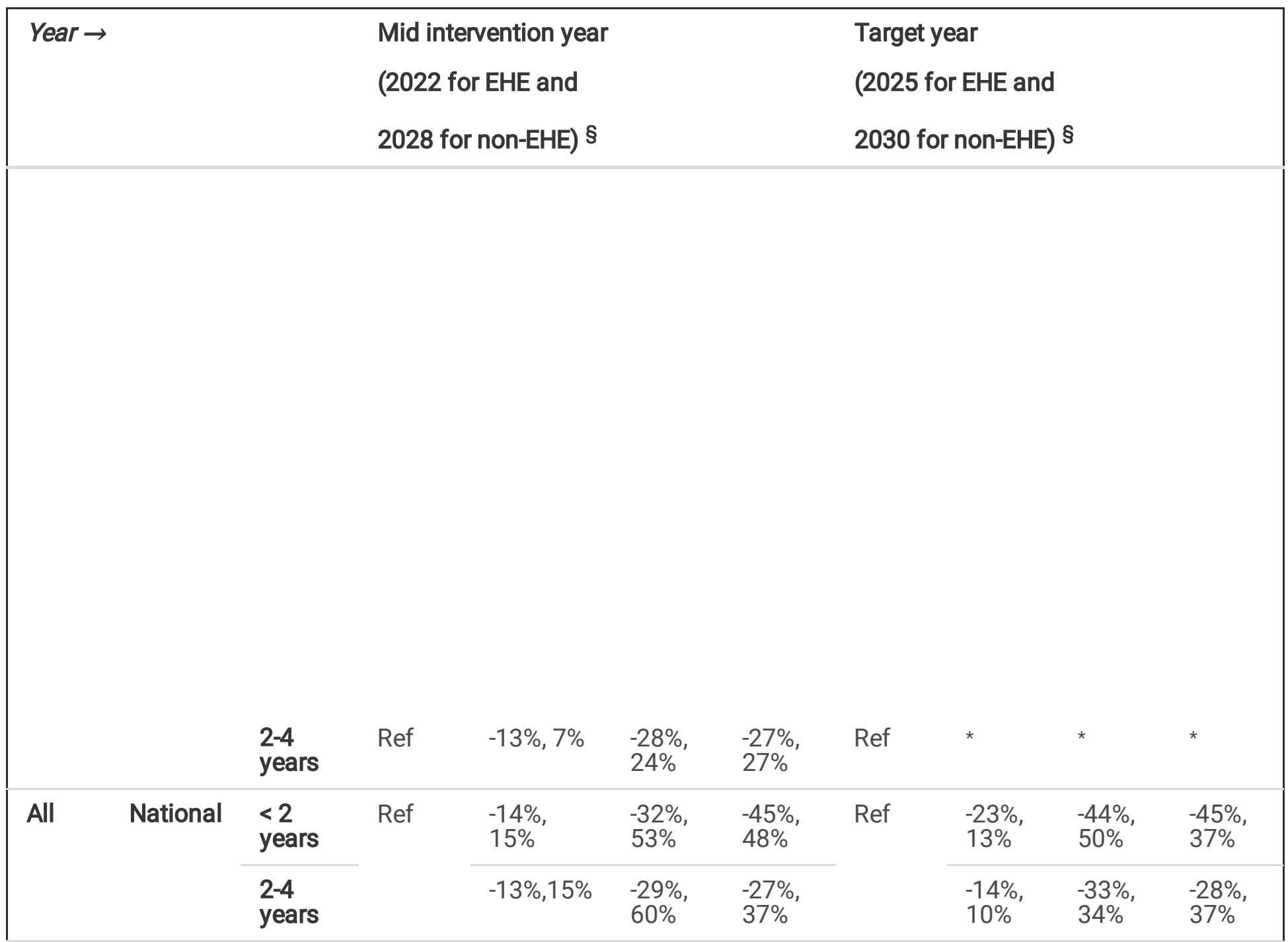

HM: Heterosexual males; HF: Heterosexual females; MSM: Men who have sex with men;

National: aggregate of all EHE and non-EHE jurisdictions; EHE: aggregate of all EHE jurisdictions; Non-EHE: aggregate of all non-EHE jurisdictions;

$+\%$ change in HIV-testing interval estimate in mixing scenarios compared to no-mixing scenario and calculated as $100 \times$ (mixing scenario - no-mixing scenario)/mixing scenario).

\# Values presented are the range (minimum, maximum) across the jurisdiction type for the specific time interval cohort (i.e., $<2$ years (minimum value was 6 months) or 2-4 years).

\Scenarios 13 to 16 scale-up care metrics (HIV-diagnosis rate, care-drop-out rate, and PrEP coverage) to reach EHE targets by 2025 for EHE jurisdictions and by 2030 for non-EHE jurisdictions.

$\S$ Results presented for mid-intervention years (2022 for EHE and 2028 for non-EHE) and target year (2025 for EHE and 2030 for non-EHE).

${ }^{*}$ No instances/scenarios were found where interval was 2-4 years. 
Table 6

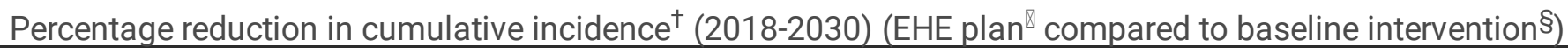

\begin{tabular}{|c|c|c|c|c|c|c|c|c|c|}
\hline \multicolumn{2}{|c|}{$\begin{array}{l}\text { Scenario no. } \rightarrow \\
\text { (reference scenario) }\end{array}$} & $\begin{array}{l}S 5^{\complement} \\
\text { (ref } \\
\left.S 1^{\S}\right)\end{array}$ & $\begin{array}{l}S 6^{\complement} \\
\text { (ref } \\
S 2^{\S} \text { ) }\end{array}$ & 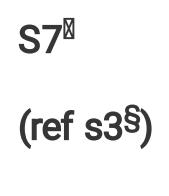 & $\begin{array}{l}S 8^{\complement} \\
\text { (ref } \\
S 4^{\S} \text { ) }\end{array}$ & $\begin{array}{l}S 13^{\bigotimes} \\
\text { (ref } \\
\text { S9§) }\end{array}$ & $\begin{array}{l}\text { S14 } \\
\text { (ref } \\
\text { S10§) }\end{array}$ & $\begin{array}{l}S 15^{\complement} \\
\text { (ref } \\
S 11^{\S} \text { ) }\end{array}$ & $\begin{array}{l}\text { S16 } \\
\text { S12 (ref }\end{array}$ \\
\hline \multicolumn{2}{|c|}{ Care assumption $\rightarrow$} & \multicolumn{4}{|c|}{ Homogeneity in care across jurisdictions* } & \multicolumn{4}{|c|}{$\begin{array}{l}\text { Heterogeneity in care across } \\
\text { jurisdictions }{ }^{\star \star}\end{array}$} \\
\hline \multicolumn{2}{|c|}{ Mixing assumption $\rightarrow$} & No- & Mixing & Mixing & Mixing & No- & Mixing & Mixing & Mixing \\
\hline $\begin{array}{l}\text { Risk group } \\
\downarrow\end{array}$ & $\begin{array}{l}\text { Jur. type } \\
\downarrow\end{array}$ & & & & & & & & \\
\hline \multirow[t]{3}{*}{ All } & National & $-24 \%$ & $-27 \%$ & $-30 \%$ & $-30 \%$ & $-30 \%$ & $-31 \%$ & $-33 \%$ & $-33 \%$ \\
\hline & EHE & $-41 \%$ & $-40 \%$ & $-38 \%$ & $-40 \%$ & $-45 \%$ & $-44 \%$ & $-41 \%$ & $-41 \%$ \\
\hline & Non-EHE & $-5 \%$ & $-14 \%$ & $-24 \%$ & $-23 \%$ & $-9 \%$ & $-15 \%$ & $-24 \%$ & $-25 \%$ \\
\hline \multirow[t]{3}{*}{$\mathrm{HM}$} & National & $-23 \%$ & $-24 \%$ & $-27 \%$ & $-27 \%$ & $-25 \%$ & $-27 \%$ & $-30 \%$ & $-30 \%$ \\
\hline & EHE & $-36 \%$ & $-35 \%$ & $-34 \%$ & $-37 \%$ & $-40 \%$ & $-39 \%$ & $-37 \%$ & $-37 \%$ \\
\hline & Non-EHE & $-4 \%$ & $-12 \%$ & $-22 \%$ & $-20 \%$ & $-9 \%$ & $-15 \%$ & $-25 \%$ & $-25 \%$ \\
\hline \multirow[t]{3}{*}{ HF } & National & $-24 \%$ & $-25 \%$ & $-28 \%$ & $-28 \%$ & $-25 \%$ & $-27 \%$ & $-30 \%$ & $-30 \%$ \\
\hline & EHE & $-38 \%$ & $-38 \%$ & $-36 \%$ & $-38 \%$ & $-43 \%$ & $-42 \%$ & $-40 \%$ & $-39 \%$ \\
\hline & Non-EHE & $-3 \%$ & $-12 \%$ & $-21 \%$ & $-20 \%$ & $-8 \%$ & $-14 \%$ & $-22 \%$ & $-23 \%$ \\
\hline \multirow[t]{3}{*}{ MSM } & National & $-25 \%$ & $-27 \%$ & $-31 \%$ & $-31 \%$ & $-32 \%$ & $-33 \%$ & $-35 \%$ & $-35 \%$ \\
\hline & EHE & $-43 \%$ & $-42 \%$ & $-40 \%$ & $-41 \%$ & $-47 \%$ & $-45 \%$ & $-42 \%$ & $-41 \%$ \\
\hline & Non-EHE & $-5 \%$ & $-14 \%$ & $-25 \%$ & $-24 \%$ & $-10 \%$ & $-16 \%$ & $-25 \%$ & $-26 \%$ \\
\hline
\end{tabular}

HM: Heterosexual males; HF: Heterosexual females; MSM: Men who have sex with men;

National: aggregate of all EHE and non-EHE jurisdictions; EHE: aggregate of all EHE jurisdictions; Non-EHE: aggregate of all non-EHE jurisdictions;

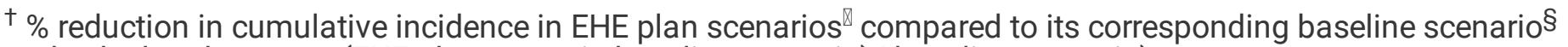
and calculated as $100 \times($ EHE plan scenario-baseline scenario)/ baseline scenario).

$\S$ Scenarios 1 to 4 and 9 to 12 keep care metrics (HIV-diagnosis rate, care-drop-out rate, and PrEP coverage) fixed at the 2018 baseline values for the full duration of the simulation.

${ }^{\square}$ Scenarios 5 to 8 and 13 to 16 scale-up care metrics (HIV-diagnosis rate, care-drop-out rate, and PrEP coverage) to reach EHE targets by 2025 for EHE jurisdictions and by 2030 for non-EHE jurisdictions.

* Scenarios 5 to 8 and 1 to 4 assume jurisdictional-homogeneity.

** Scenarios 9 to 12 and 13 to 16 assume jurisdictional-heterogeneity.

\section{Figures}




\section{Figure 1}

Compartmental simulation: Transition diagram with care continuum and disease stages

$\delta_{d}$ : diagnostic rate in disease stage $d$,

I: proportion linked to care within three months of diagnosis,

$\rho:$ care drop-out rate, and

Y: rate of re-entry to care.

\section{Figure 2}

Comparing annual risk-group specific incidence projections between NHSS, National-Model, and JurisdictionalModel $^{*}$

NHSS: National HIV Surveillance System; NHSS-National: national-level estimates from NHSS;

*Using period 2011 to 2019 to validate that National-Model simulated estimates are within range of NHSS estimates; using period 2018 to 2019 to verify that Jurisdictional-Model simulated estimates (from scenarios S1 to S4 ${ }^{\dagger}$, and S9 to $S 12^{\ddagger}$ ) generate incidence in magnitudes similar to National-Model estimates; and using period 2020 to 2030 to observe differences between Jurisdictional-Model scenarios S1, S2, S3, S4, S9, S10, S11, and S12.

† Scenarios S5, S6, S7, and S8, start at the same baseline (2018) as S1, S2, S3, and S4, respectively.

‡ Scenarios S13, S14, S15, and S16, start at the same baseline (2018) as S9, S10, S11, and S12, respectively.

\section{Figure 3}

Comparing annual incidence projections between 16 scenarios simulated in Jurisdictional-Model and NHSS estimates*

NHSS: National HIV Surveillance System; NHSS-National: national-level estimates from NHSS

*Using period 2018 to 2019 to verify that Jurisdictional-Model simulated estimates generate incidence in magnitudes similar to NHSS estimates; and using period 2020 to 2030 to observe differences between Jurisdictional-Model scenarios S1 to S16.

${ }^{\dagger}$ Scenarios S1 to S8 assume jurisdictional-homogeneity; Scenarios S9 to S16 assume jurisdictional-heterogeneity; Scenarios S1 to S4 and S9 to S12 assume baseline intervention; Scenarios S5 to S8 and S13 to S16 scale-up interventions as per EHE-plan. 


\section{Figure 4}

Comparing annual incidence between 16 scenarios simulated in Jurisdictional-Model, aggregated by EHE and nonEHE jurisdictions

†Scenarios S1 to S8 assume jurisdictional-homogeneity; Scenarios S9 to S16 assume jurisdictional-heterogeneity; Scenarios S1 to S4 and S9 to S12 assume baseline intervention; Scenarios S5 to S8 and S13 to S16 scale-up interventions as per EHE-plan.

\section{Figure 5}

a: Comparing percentage change in incidence estimates for no-mixing compared to mixing (EHE jurisdictions*, baseline, 2018)

Level-1: Scenario S14; Level-2: Scenario S15; and Level-3: Scenario S16

* The title on each subplot is the EHE jurisdiction (county or state) along with values of incidence in year 2018 under the no-mixing scenario [S13]

b: Comparing percentage change in incidence estimates for no-mixing compared to mixing (non-EHE jurisdictions*, baseline, 2018)

Level-1: Scenario S14; Level-2: Scenario S15; and Level-3: Scenario S16

* The title on each subplot is the non-EHE jurisdiction (state) along with values of incidence in year 2018 under the no-mixing scenario [S13]

\section{Figure 6}

See image above for figure legend.

\section{Supplementary Files}

This is a list of supplementary files associated with this preprint. Click to download.

- Appendixjurmodel12312021.docx 